\title{
Rain Rate Distributions for Microwave Link Design Based on Long Term Measurement in Malaysia
}

\author{
Islam Md Rafiqul, Md Moktarul Alam, Ali Kodhim Lwas and Sarah Yasmin Mohamad \\ Department of Electrical and Computer Engineering, Faculty of Engineering \\ International Islamic University Malaysia, Jalan Gombak, 53100 Kuala Lumpur, Malaysia
}

\begin{abstract}
Article Info
Article history:

Received Jan 15, 2018

Revised Mar 12, 2018

Accepted Mar 28, 2018

Keywords:

Microwave propagation

Rain attenuation

Rain rate distribution

ABSTRACT

Attenuation due to rain is an important constraint in microwave radio link design especially at frequencies above $10 \mathrm{GHz}$. It restricts the path length of radio communication systems and limits the use of higher frequencies for line-of-sight microwave links and satellite communications. In order to predict the attenuation due to rain accurately rainfall intensity is required with 1-minute integration time. Rainfall is a meteorological phenomenon with complex structure due to its variability in space, duration and occurrence frequency, particularly in tropical and equatorial regions. Since, the statistical distribution of rain attenuation is obtained from the rain rate distribution for the region considered, it should be noted that the accuracy of the rain rate measurement affects the accuracy of the attenuation estimation. This paper presents rain intensity with 1-minute integration time measured for 6 years in Malaysia, it's distribution, comparison with other prediction models and impact on high frequency microwave links.
\end{abstract}

Copyright (C) 2018 Institute of Advanced Engineering and Science. All rights reserved.

\section{Corresponding Author:}

Md Rafiqul Islam, Department of Electrical and Computer Engineering, Intenational Islamic University, Malaysia, E1 building, Khulliyah of Engineering, IIUM, Gombak 53100, Selangor, Malaysia. Email: rafiq@iium.edu.my

\section{INTRODUCTION}

The effect of the earth's atmosphere on radio waves propagating earth and space is a constant concern in the performance of communication systems. These conditions can cause uncontrolled variations in signal amplitude, phase, polarization and angle of arrival which result in a reduction in the quality of analog transmission and an increase in the error rate of transmissions. Consequently, statistical analyses and techniques are generally most useful for evaluation of transmission impairments on communications link [1].

The classical development for the determination of rain attenuation on a transmitted radio wave is based on three assumptions describing the nature of radio wave propagation and precipitation. First, the intensity of the wave decays exponentially as it propagates through the volume of rain. Then the raindrops are assumed to be spherical water drops, which both scatter and absorb energy from the incident radio wave. And the contributions of each drop are additive and independent of the other drops. This implies a 'single scattering' of energy, however, the empirical results of the classical development do allow for some 'multiple scattering' effects [2]-[3].

In microwave link design, there are several effects on microwave link need to be considered due to atmosphere propagation between earths to free space. These conditions can cause uncontrolled variations in signal amplitude, phase, polarization, and angle of arrival, which result in a reduction in the quality of analog transmissions and an increase in the error rate of digital transmissions. The relative importance of radio wave propagation in space communications depends on the frequency of operation, local climatology, local geography, type of transmission, and elevation angle to the satellite [4]-[5]. 


\section{RAIN RATE DISTRIBUTION}

The prediction of rain rate distribution is based on four models which are Global Moupfouma, modified Moupfouma, ITU-R and Crane Global Model. Usually, the rain rate is the basic parameter to determine the rain attenuation prediction. The rain rate usually depends on the geography region. The previous researchers like Crane [4] and ITU-R [5]-[6] recommendation already classify the whole world into several zones.

\subsection{Global Moupfouma Model}

The Moupfouma model is one of the many approximation models useful in the estimation of rain rate in tropical and temperate regions; others include the gamma model and Log-normal model. In global Moupfouma [7], The cumulative distribution of rain rate equation for Moupfouma model is:

$$
P(R \geq r)=\left(\frac{R_{0.01}+1}{r+1}\right)^{b} \times e^{\left[u \times\left(R_{0.01}-r\right)\right]-\log _{e}\left(10^{4}\right)}
$$

Where $r$ is $(\mathrm{mm} / \mathrm{h})$ represents the rain- rate exceeded for a fraction of the time. $\mathrm{R}$ is the rain rate in $\mathrm{mm} / \mathrm{hr}$ and $\mathrm{R}_{0.01 \%}$ is the rain rate in $\mathrm{mm} / \mathrm{hr}$ at $0.01 \%$ of time of a year. Considering the behavior of the shape of cumulative distribution for rainfall rate, $\mathrm{b}$ is approximately by the following analytical expression

Where,

$$
\mathrm{b}=\left(\frac{\mathrm{r}-R_{0.01}}{R_{0.01}}\right) \times \log _{\mathrm{x}}\left(1+\frac{\mathrm{r}}{R_{0.01}}\right)
$$

For tropical region,

$$
u=\frac{\log _{e}\left(10^{4}\right)}{R_{0.01}} \times e^{-\lambda \times\left(r / R_{0.01}\right) \gamma}
$$

Where, $\lambda=1.066$ and $\gamma=0.214$

In this paper, the values are used as above, since Malaysia is in tropical region.

\subsection{Modified Moupfouma Model}

To estimate $R_{0.01}$, Chebil's model appears suitable and it allows the usage of long-time mean annual accumulation, M, at the location [7]. The power law of the model is given by,

$$
\mathrm{R}_{0.01 \%}=\alpha M^{\beta}
$$

Where $\alpha$ and $\beta$ are regression coefficients.

Chebil has made a comparison between some models based on measured values of $R_{0.01}$ and $\mathrm{M}$ in Malaysia, Indonesia, Brazil, Singapore and Vietnam. He showed that his model is the best estimate of the measured data [8]. The regression coefficient $\alpha$ and $\beta$ are defined as,

$$
\alpha=12.2903 \text { and } \beta=0.2973
$$

In modified Moupfouma, the equation used is similar to the global Moupfouma for predicting other constant such as value of $\alpha$ and $\beta$ [7].

\subsection{ITU-R Model}

In ITU-R [5], [6], the region of concerned is determined based on the rain region which recommended by ITU-R [5], [6], [9]. In this case, the concerned region is region P for Malaysia as shown in Figure 1 [6]. The rain rates for different percentages of time for region $\mathrm{P}$ are presented in Table 1.

Table 1. Rain rate intensity proposed by ITU-R [6]

\begin{tabular}{cc}
\hline Percentage of Time, \%P & Rain Rate at P \\
\hline 1 & 12 \\
0.3 & 34 \\
0.1 & 64 \\
0.03 & 105 \\
0.01 & 145 \\
0.003 & 200 \\
0.001 & 250 \\
\hline
\end{tabular}




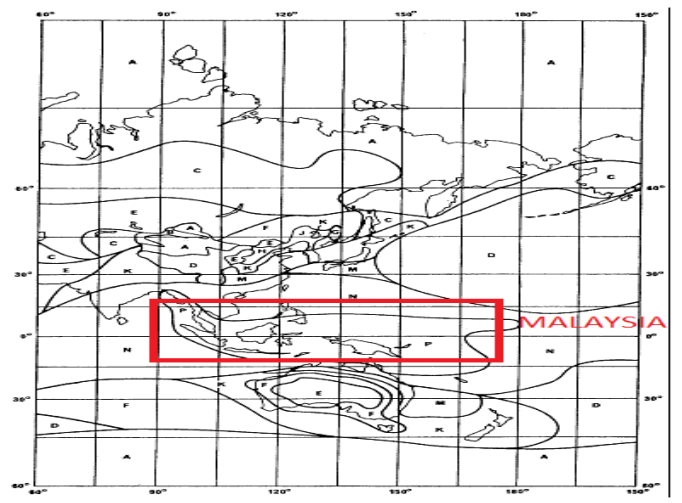

Figure 1. Rain rate distributions for Asia, Oceania and Australia [6]

\subsection{Crane Model}

Crane's global model divides the world from $\mathrm{A}$ to $\mathrm{H}$ regions based on rain rate distributions. The concerned region is Malaysia and it is in H-region. The rain rates for different percentages of time for region $\mathrm{H}$ proposed by Crane [4], [10] are presented in Table 2.

Table 2. Point Rain Rate (Rp) Distribution values ( $\mathrm{mm} / \mathrm{hr}$ ) versus percent of year Rain Rate is Exceeded [10]

\begin{tabular}{cr}
\hline Percent of year & Rain Climate H region \\
\hline 0.001 & 251 \\
0.002 & 220 \\
0.005 & 178 \\
0.01 & 147 \\
0.02 & 115 \\
0.05 & 77 \\
0.1 & 51 \\
0.2 & 31 \\
0.5 & 13 \\
1 & 6.4 \\
2 & 2.8 \\
\hline
\end{tabular}

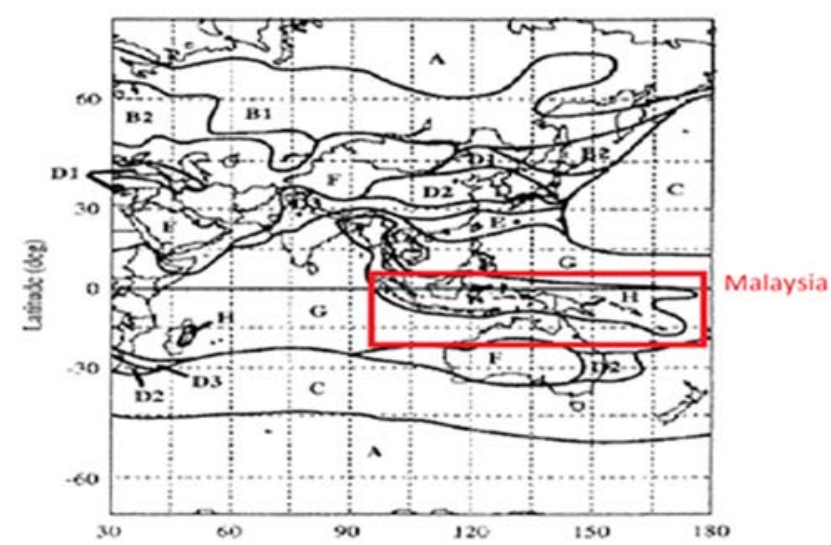

Figure 2. Rain rate distributions for Asia [4], [10]

\section{MEASUREMENT SET UP}

The real-time rain guage was installed at IIUM Campus. The data was collected for 6 years period from 2011-2016. The rain gauge as in Figure 3 is manufactured entirely from non-corrosive materials. The base and septum ring are the cast in Aluminum Alloy LM25, heat treated and protectively coated. The outer ring and funnel are fabricated from aluminum alloy sheet and again protectively coated. Stainless steel mesh is employed to protect the inlet and outlet ports from the ingress of foreign bodies [8]. Casella Tipping 
Bucket Gauges are reliable and extremely robust devices. Some version has a built-in logger to store rainfall data while others can have a heater fitted to the base of the unit to prevent freezing. The rain gauges comprise a light weight injection molded plastic divided 'tipping bucket' assembly with stainless steel pins to support assembly. Rain will be collected in one side of the buckets, and the volume of the water is predetermined. When one of the buckets is full, the water will be discharged and it will change to fill the water to the other side of the bucket depends on the specification as given in Table 2, the weight of the water causes it to tip and empty itself. Each time a tip, an electrical contact is made, thereby enabling recording or rainfall amount and intensity with time. The maximum detectable rainfall rate is $200 \mathrm{~mm} / \mathrm{hr}$. Rain fall data is being recorded for every 10 seconds of time. Each side of the bucket will accumulate $0.2 \mathrm{~mm}$ of water. Therefore, once the bucket is changed, the data will be recorded [11]-[14].

Table 3. The technical specifications of the Casella Tipping Bucket Gauge

\begin{tabular}{ll}
\hline Bucket Size & $0.2 \mathrm{~mm}$ \\
\hline Aperture & $400 \mathrm{~cm}^{2}$ \\
Accuracy & $\pm 2 \%$ at 1 litre/hour \\
Capacity & Unlimited \\
Transducer & Magnet/Reed switch \\
Operating Tempreture & $1^{\circ} \mathrm{C}$ to $85^{\circ} \mathrm{C}$ \\
Range & \\
Weight & $2.6 \mathrm{~kg}$ \\
\hline
\end{tabular}

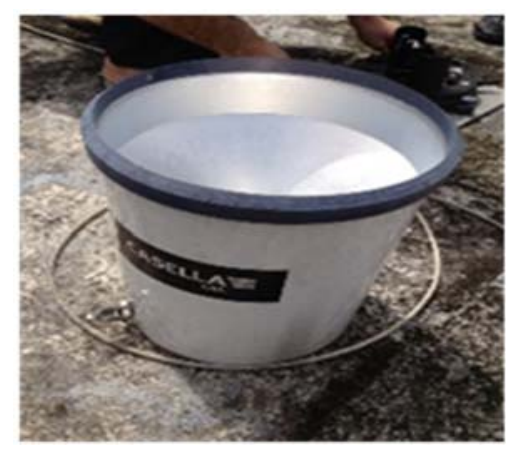

Figure 3. Casella Tipping Bucket Rain Gauge

\section{RESULTS AND ANALYSIS}

\subsection{Monthly Distribution}

Monthly variations of measured rain rate cumulative distributions for the year 2014 is shown in Figure 4. The rain rate is calculated as $\% \mathrm{P}$ using 1 -minute integration time and presented in $\mathrm{mm} / \mathrm{hr}$. The highest rainfall intensity $240 \mathrm{~mm} / \mathrm{hr}$ is observed in June while lowest in February. From the graph, $0.01 \%$ of time, the rain is recorded $160 \mathrm{~mm} / \mathrm{hr}$ in June and $70 \mathrm{~mm} / \mathrm{hr}$ in February, while $120 \mathrm{~mm} / \mathrm{hr}$ in annual average. Pattern of all distributions are similar in trends.

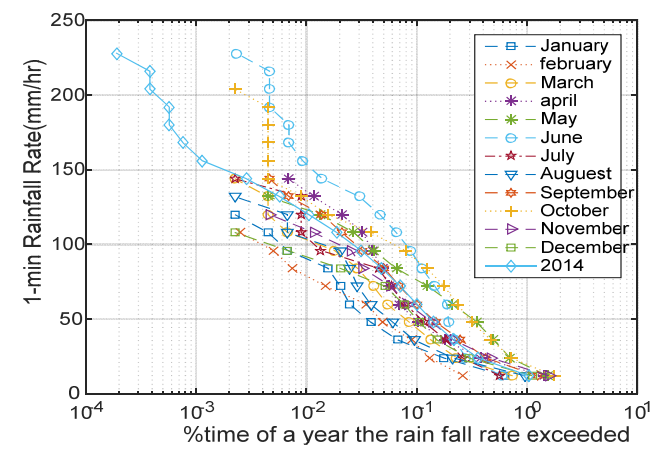

Figure 4. Monthly variations of measured rain rate distribution with 1-minute integrationtime for the year 2014

Indonesian J Elec Eng \& Comp Sci, Vol. 10, No. 3, June 2018 : 1023 - 1029 


\subsection{Yearly Distribution}

For yearly variations, six years rain rate cumulative distributions of measured data with 1- minute integration time and six years average are presented in Figure 5. From distributions, it is obvious that in 2014 measurement has the highest rain rate while 2016 is the lowest. The measured rain rate of 2014 is slightly higher than the average while rain rate measured in 2016 is much lower than the average. For 0.01 percent of time, six years average rain rate is found as $110 \mathrm{~mm} / \mathrm{hr}$ while the annual rain rates are found 119, 110, 100, 124, 110 and $97 \mathrm{~mm} / \mathrm{hr}$ for 2011, 2012, 2013, 2014, 2015 and 2016 respectively.

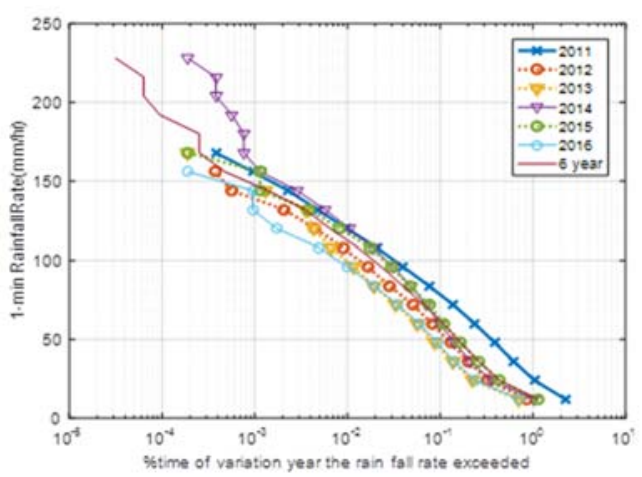

Figure 5. Yearly variations of rain rate distribution measured with 1-minute integration time for the year from 2011 to 2016

\subsection{Comparisons Between Measurements and Predictions}

The measured rain rate from 2011 to 2013 at IIUM Campus is compared with those predicted by Global Moupfouma, Crane and ITU-R models and shown in Figure 6(a). The same comparison is done for data measured from 2014 to 2016 and shown in Figure 6(b). Both figures show that predictions by ITU-R and Crane model are close to measurements for $0.1 \%$ and higher and overestimate the measurement at lower percentages of time. Moupfouma model overestimates the measurements in both figures.

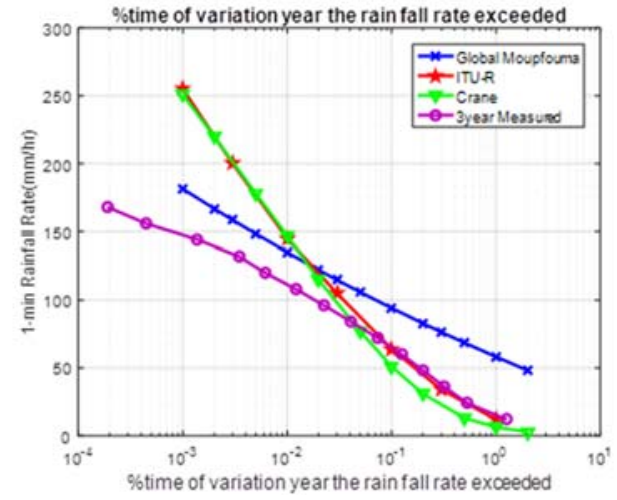

(a)

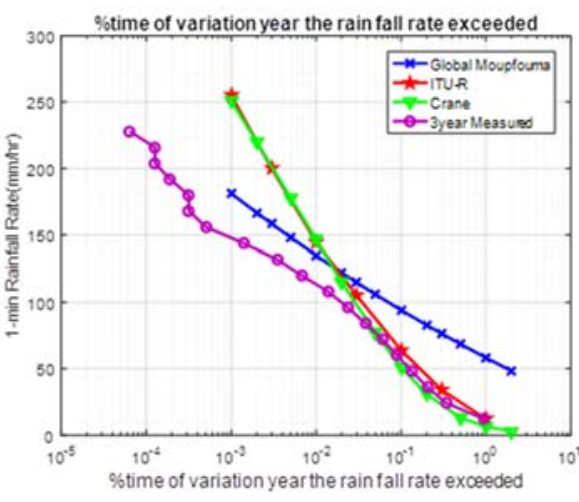

(b)

Figure 6. Comparison between the measured rain rates for the years (a) 2011-2013 and (b) 2014-2016 and those predicted by available models

The average of 6 years measurement is compared with those predicted by Global Moupfouma, Crane and ITU-R models and shown in Figure 7. From Figure, it is obvious that predictions by ITU-R and Crane model are close to measurements for 0.1 and higher percentages of times. However, both models overestimate the six years measurement in Malaysia at all lower percentages of time. At $0.001 \%$, both models overestimate more than $100 \mathrm{~mm} / \mathrm{hr}$ from measurements. Moupfouma model overestimates the measurements in all percentages. It overestimates $50 \mathrm{~mm} / \mathrm{hr}$ and $25 \mathrm{~mm} / \mathrm{hr}$ for $1 \%$ and $0.01 \%$ respectively. It 
is observed for 0.01 percentage of time, measured six years average rain rate is $110 \mathrm{~mm} / \mathrm{hr}$, while 135,147 and $145 \mathrm{~mm} / \mathrm{hr}$ are predicted by Global Moupfouma, Crane and ITU-R models. At $0.01 \%$ of time, the measured rain rate is found $110 \mathrm{~mm} / \mathrm{hr}$, while ITU-R latest recommendation [5] has proposed $100 \mathrm{~mm} / \mathrm{hr}$ rain intensity for Malaysia at $0.01 \%$ time.

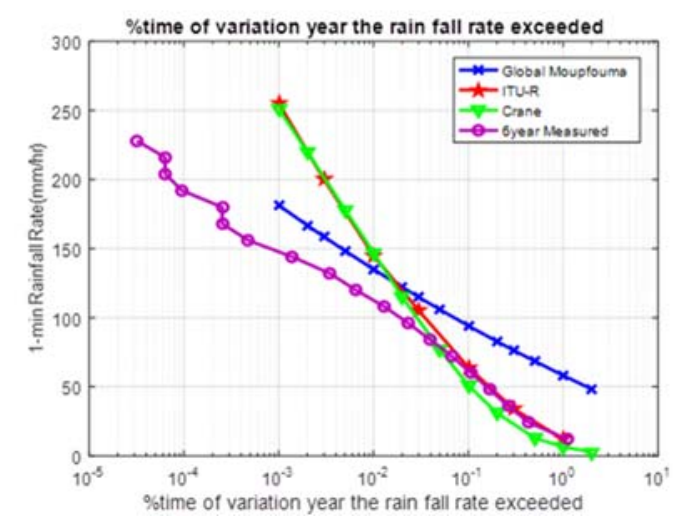

Figure 7. Comparison between the available rain rate Model and 6-years measurement

\subsection{Rain Attenuation Prediction}

ITU-R prediction method [9], [15] is used to estimate earth-to-satellite link's rain attenuation for four frequency bands using ITU-R [5], [16] predicted rain rate of $100 \mathrm{~mm} / \mathrm{hr}$ and measured rain of 110 $\mathrm{mm} / \mathrm{hr}$ for $0.01 \%$ of time. Reference satellite is assumed as MESAT3 with an elevation angle of $77.4^{\circ}$ from satellite Lab at IIUM campus where the six years rain rate were measured. All signals for four bands are considered as vertical polarization and predicted attenuations are presented in Figure 8. It is obvious that the higher frequency band causes the high attenuation. At $0.01 \%$, predicted attenuations using measured rain rate are found 46, 33, 18 and $2 \mathrm{~dB}$ for $\mathrm{V}, \mathrm{Ka}, \mathrm{Ku}$ and $\mathrm{C}$-bands respectively. Predicted attenuations using ITU-R recommended rain rate are found $5 \mathrm{~dB}, 3 \mathrm{~dB}$ and $1 \mathrm{~dB}$ lower than that predicted by measured rain rates for $0.01 \%$ for $\mathrm{V}, \mathrm{Ka}$ and $\mathrm{Ku}-$ bands respectively.

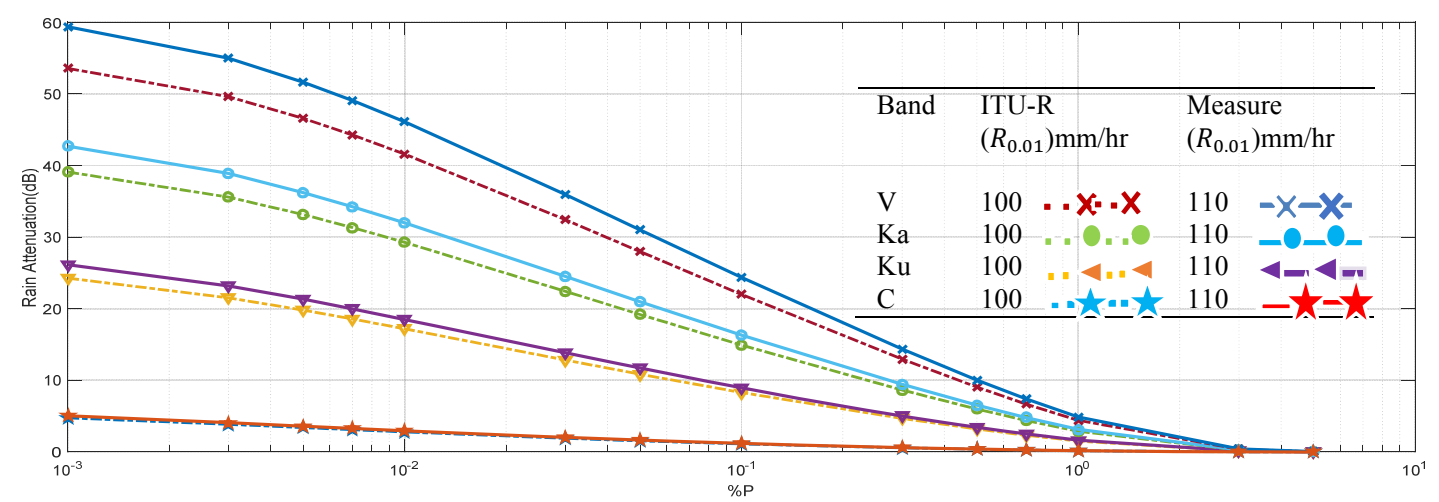

Figure 8. Predicted rain attenuations at $\mathrm{V}, \mathrm{Ka}, \mathrm{Ku}$ and $\mathrm{C}$-bands using ITU-R prediction method based on measured rain rate with 1-minute integration time and ITU-R predicted rain rate

\section{CONCLUSION}

In order to predict the attenuation due to rain accurately, rainfall intensity is required with 1-minute integration time. Rain intensity with 1-minute integration time were measured for 6 years at IIUM Kuala Lumpur campus in Malaysia. Monthly and yearly statistical distributions of measured rain rate are presented. Moupfouma, Crane and ITU-R models for rain rate distributions are compared with measured rain rates. All models overestimate the measurements most of time in measured year. It is observed for 0.01 percentage of time, measured six years average rain rate is $110 \mathrm{~mm} / \mathrm{hr}$, while 135,147 and $145 \mathrm{~mm} / \mathrm{hr}$ are predicted by Global Moupfouma, Crane and ITU-R models for Malaysia. At $0.01 \%$ of time, the measured rain rate is found $110 \mathrm{~mm} / \mathrm{hr}$ while ITU-R latest recommendation has proposed $100 \mathrm{~mm} / \mathrm{hr}$ rain 
intensity for Malaysia. ITU-R prediction method is used to estimate earth-to-satellite link's rain attenuation for four frequency bands using ITU-R predicted rain rate of $100 \mathrm{~mm} / \mathrm{hr}$ and measured rain of $110 \mathrm{~mm} / \mathrm{hr}$. The higher frequency band causes the higher attenuation. At $0.01 \%$, predicted attenuations using measured rain rate are found 46, 33, 18 and 2 $\mathrm{dB}$ for $\mathrm{V}, \mathrm{Ka}, \mathrm{Ku}$ and $\mathrm{C}$-bands respectively. Predicted attenuations using ITU-R recommended rain rate are found $5 \mathrm{~dB}, 3$ $\mathrm{dB}$ and $1 \mathrm{~dB}$ lower than that predicted by measured rain rates for $0.01 \%$ for $\mathrm{V}, \mathrm{Ka}$ and $\mathrm{Ku}$-bands respectively.

\section{ACKNOWLEDGEMENTS}

Authors are grateful to Research Management Centre, International Islamic University Malaysia to support this research through research grant RIGS16-065-0229.

\section{REFERENCE}

[1] Louis J. Ippolito, J, "Satellite Communications Systems Engineering: Atmospheric Effects, Satellite Link Design and System Performance", 2nd Edition, John Wiley \& Sons, Ltd., 2017.

[2] L.Freeman, R, "Radio System Design for Telecommunications" John Wiley \& Sons, 2007.

[3] L.J.Ippolito, "Radiowave Propagation in Satellite Communicayion", 1986.

[4] R.K.Crane,"Electromagnetic Wave Propagation through Rain",New York: John Wiley \& Sons, 1996.

[5] ITU-R."Characteristic of precipitation fro Propagation Model.”, P.837-7, June 2017.

[6] Rec. ITU-R, "Characteristics of Preception for Propagation Modeling", PN 837-1,1994.

[7] Moupfouma, F., "Point Rainfall Rate Cumulative Distribution Fnction Valid at Various Locations", Electronic Letters, Vol. 29, 1993.

[8] J.Chebil \&T.A.Rahman, "Development of 1 min Rain Rate Contour Maps for Microwave Application in Malaysia Peninsula", Electronics Letters, 1999.

[9] ITU-R., "Rain height model for prediction methods". P.839-4. ,Sept. 2013.

[10] R.K. Crane, "Prediction of attenuation by rain", IEEE Transaction on Communication., Vol. COM-28, No. 9, pp. 1717-1733, September 1980.

[11] Hasan dao, Md Rafiqul Islam and Khalid A. S. Al-Khateeb, "Rain Fade Slope Model in Satellite Path Based on Data Measured in Heavy Rain Zone," IEEE Antennas and Wireless Propagation Letters, VOL. 12, 2013.

[12] Ahmed A. Basahel, Md. Rafiqul Islam, Suriza A. Zabidi, and Mohamed H. Habaebi, "Availability Assessment of Free-Space-Optics Links with Rain Data from Tropical Climates", Journal of Lightwave Technology, VOL. 35, pp. 19, Oct. 1, 2017.

[13] Ahmed Basahel, Md. Rafiqul Islam, Suriza A. Z, and Mohamad Hadi Habebi, "Effect of Rain \& Haze on Availability of Terrestrial Free Space Optical Link Under Tropical Weather Conditions”, International Conference on Computer \& Communication Engineering, 2016.

[14] Islam Md. Rafiqul, Ali Kadhim Lwas, Mohamed Hadi Habaebi, "Site diversity gain for earth-to-satellite links using rain intensity measurement", Indonesian Journal of Electrical Engineering and Informatics (IJEEI), 5 (4)., 0 pp. 330-338. ISSN 2089-3272, 2017.

[15] ITU-R., "Propagation data and prediction methods required for the design of earth-space telecommunication systems", P.618-12, July 2015.

[16] ITU-R, Specific attenuation model for rain use in prediction methods", P. 838-3, March 2005. 